\title{
Leishmaniose tegumentar americana: apresentação pouco comum*
}

\author{
American tegumentary leishmaniasis: an unusual \\ presentation
}

\begin{abstract}
Antonio Carlos Martins Guedes ${ }^{1} \quad$ Maria de Lourdes R. de Carvalho $^{2} \quad$ Maria Norma Melo
Resumo: Relata-se caso de leishmaniose tegumentar americana com lesões proeminentes na face. Os critérios diagnósticos incluíram dados clínicos e epidemiológicos, intradermorreação de Montenegro, identificação de Leishmania pela reação em cadeia da polimerase e resposta clínica ao tratamento. A importância do relato se deve ao fato de se tratar de caso incomum de leishmaniose tegumentar americana. Palavras-chave: Leishmania; Leishmaniose; Leishmaniose cutânea; Reação em cadeia da polimerase
\end{abstract}

Abstract: We report the case of a patient with American cutaneous leishmaniasis and prominent lesions on the face. Diagnostic criteria included clinical and epidemiological data, Montenegro's skin test, identification of Leishmania by means of polymerase chain reaction and clinical response to treatment. Our report is important to call attention to an unusual presentation of American cutaneous leishmaniasis.

Keywords: Leishmania; Cutaneous leishmaniasis; Leishmania; Leishmaniasis; Polymerase chain reaction

\section{INTRODUÇÃO}

As leishmanioses são infecções crônicas, não contagiosas, que afetam milhões de pessoas em todo o mundo, causadas por diversas espécies de protozoários do gênero Leishmania e transmitidas de animais para o homem por fêmeas de flebotomíneos infectadas. ${ }^{1}$

Até o momento, seis espécies de Leishmania, pertencentes aos subgêneros Leishmania e Viannia, foram identificadas no Brasil como causadoras de leishmaniose tegumentar americana (LTA) humana: 1Leishmania (Viannia) braziliensis: é a espécie mais prevalente no homem e pode causar lesões cutâneas e mucosas, 2- Leishmania (V.) guyanensis, 3Leishmania (V.) naiffi, 4- Leishmania (V.) shawi, 5Leishmania (V.) lainsoni, 6- Leishmania (Leishmania) amazonensis. ${ }^{2,3}$

A leishmaniose tegumentar americana apresenta-se em fase de expansão geográfica. Nas últimas décadas, as análises de estudos epidemiológicos de LTA têm sugerido mudanças no comportamento epidemiológico da doença. Inicialmente considerada zoonose de animais silvestre que acometia ocasionalmente pessoas em contato com florestas, a LTA começa a ocorrer em zonas rurais já praticamente desmatadas e em regiões periurbanas. Observa-se a coexistência de um duplo perfil epidemiológico, expresso pela manutenção de casos oriundos dos focos antigos ou de áreas próximas a eles, e pelo aparecimento de surtos epidêmicos associados a fatores decorrentes do surgimento de atividades econômicas como garimpos, expansão de fronteiras agrícolas e extrativismo, em condições ambientais altamente favoráveis à transmissão da doença. ${ }^{4}$

Pode apresentar-se em diferentes formas clínicas, dependendo da espécie de Leishmania e da relação do parasito com seu hospedeiro, ${ }^{5}$ sendo con-

\footnotetext{
Recebido em 21.07.2007.

Aprovado pelo Conselho Consultivo e aceito para publicação em 17.04.2008

* Trabalho realizado no Serviço de Dermatologia - Hospital das Clínicas - Universidade Federal de Minas Gerais (UFMG) - Belo Horizonte (MG), Brasil.

Conflito de interesse: Nenhum / Conflict of interest: None

Suporte financeiro: / Financial funding: Conselho Nacional de Desenvolvimento Científico e Tecnológico (CNPq) e Fundação de Amparo à Pesquisa do Estado de Minas Gerais (Fapemig).

Professor adjunto de dermatologia do Departamento de Clínica Médica da Faculdade de Medicina da Universidade Federal de Minas Gerais (UFMG) - Belo Horizonte (MG), Brasil. Doutor em dermatologia pela Universidade Federal de São Paulo (Unifesp) - São Paulo (SP), Brasil.

Médica dermatologista, doutora em ciências - Área de Concentração: Imunoparasitologia - do Instituto de Ciências Biológicas da Universidade Federal de Minas Gerais (UFMG) - Belo Horizonte (MG), Brasil.

Professora titular do Departamento de Parasitologia do Instituto de Ciências Biológicas da Universidade Federal de Minas Gerais (UFMG) - Belo Horizonte (MG), Brasil.

(C)2008 by Anais Brasileiros de Dermatologia
} 
hecidas três formas de leishmaniose: a cutânea (restrita à pele), a cutâneo-mucosa (acomete pele e mucosas) e visceral (afeta órgãos do sistema reticuloendotelial). ${ }^{6}$

O diagnóstico de LTA abrange aspectos epidemiológicos, clínicos e laboratoriais (pesquisa parasitológica e de diagnóstico imunológico). Freqüentemente a associação de alguns desses elementos é necessária para se chegar ao diagnóstico final. ${ }^{7} \mathrm{O}$ diagnóstico clínico da LTA pode ser feito com base nas características da lesão associadas à anamnese, em que os dados epidemiológicos são de grande importância. ${ }^{8}$

Em estudo extenso e clássico de LTA no Brasil, Magalhães et al. ${ }^{9,10}$ analisaram biópsias de 378 pacientes infectados com $L$. braziliensis que, através das alterações dérmicas ou do córion da mucosa, permitiram identificar a existência de cinco padrões histopatológicos: 1- reação exsudativa celular; 2reação exsudativa e necrótica; 3 - reação exsudativa e necrótico-granulomatosa; 4- reação exsudativa e granulomatosa; e 5- reação exsudativa e tuberculóide.

A reação em cadeia da polimerase (polymerase chain reaction) - PCR é exame que permite amplificar em escala exponencial seqüências de DNA. Dotada de excepcional sensibilidade, é capaz de detectar quantidades tão pequenas quanto um fentograma (que corresponde $\mathbf{a}^{10-15} \mathrm{~g}$ ) do DNA de uma leishmânia, o equivalente a 1/10 do parasita. ${ }^{11}$ Brujin e Barker ${ }^{11}$ seqüenciaram minicírculos do kDNA de três espécies do complexo L. braziliensis (L. braziliensis, L. guyanensis, $L$. peruviana e parte do minicírculo de L. panamensis) e selecionaram um par de oligonucleotídeos (iniciadores) os quais amplificam os minicírculos de kDNA das espécies pertencentes a esse complexo. Eresh et al. ${ }^{12}$ seqüenciaram iniciadores do kDNA de $L$. amazonensis altamente específicos para espécies do complexo $L$. mexicana e que podem também ser usados para distinguir isolados de $L$. (L.) mexicana e $L$. (L.) amazonensis. Esses iniciadores são potencialmente úteis no diagnóstico de leishmaniose tegumentar do Novo Mundo e em pesquisas epidemiológicas. ${ }^{12}$ Entretanto, as exigências técnicas e o custo relativamente elevado ainda limitam seu emprego rotineiro. No Brasil foi determinada sensibilidade de $98,41 \%$ e especificidade de $95,59 \% .^{13}$

\section{RELATO DO CASO}

Paciente do sexo feminino, 22 anos, natural e procedente de Vargem da Palma - MG. Em julho de 2002, a paciente notou lesões simétricas acne-símiles nas regiões malares, com base eritematosa e crescimento progressivo. Subseqüentemente, notou edema periorbitário, febre e cefaléia. Havia tomado $180 \mathrm{com}$ primidos de tetraciclina, e usado corticóide e antibiótico tópicos e bloqueador solar, sem melhora. Três meses após biópsia, o laudo histopatológico mostrou dermatite liquenóide não classificada. Diante disso relata que foi tratada com cloroquina por 220 dias, tendo suspeita diagnóstica de lúpus eritematoso discóide, não apresentando melhora do quadro.

Em setembro de 2003, sem melhora das lesões (Figura 1), procurou o Serviço de Dermatologia da Universidade Federal de Minas Gerais, sendo então realizados PPD (nódulo $10 \mathrm{~mm}$ ), intradermorreação de Montenegro (nódulo $11 \mathrm{~mm}$ ), reação de imunoflurescência indireta para Leishmania sp (nega-

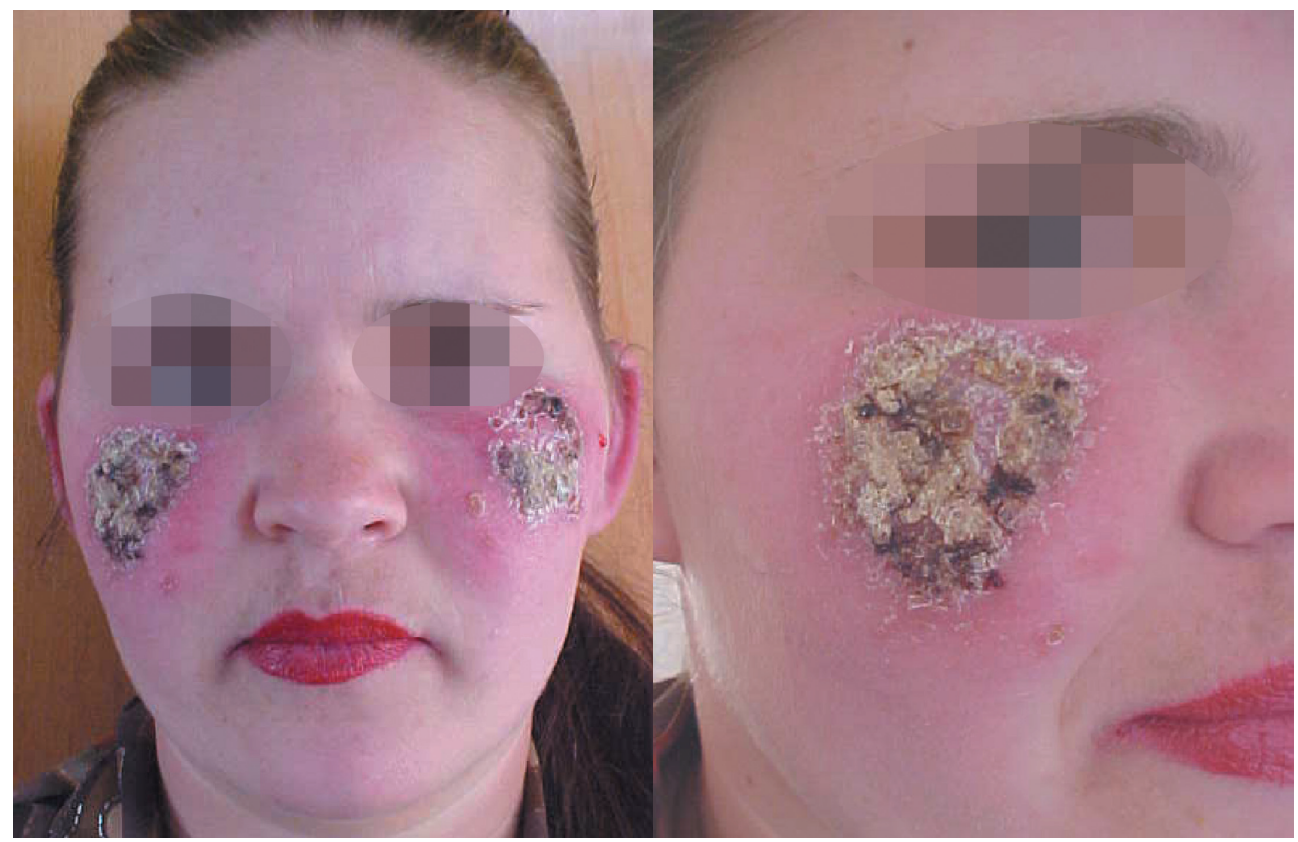

FiguRA 1: : Lesão ulcerocrostosa em base eritêmato-infiltrada acometendo a região malar, bilateralmente (setembro de 2003) 
tiva) e biópsia, que revelou infiltrado granulomatoso (Figuras 2 e 3). No material parafinado utilizado para o exame de histopatologia foi realizada a PCR, que mostrou produtos amplificados de Leishmania $s p$. Foram empregados iniciadores específicos para $\mathrm{O}$ gênero Leishmania $5^{\circ}(\mathrm{G} / \mathrm{C}) \quad(\mathrm{G} / \mathrm{C}) \quad(\mathrm{C} / \mathrm{G}) \quad \mathrm{CC}(\mathrm{A} / \mathrm{C})$ CTAT(A/T) TTACACAACCC 3 e $5^{\prime}$ GGGGACGGGCGTTCTGCGAA, que amplificam fragmento de 120 pb da região conservada do kDNA do minicírculo de Leishmania. As reações de PCR foram processadas para volume final de $10 \mu \mathrm{L}$, sendo utilizado o DNA extraído de material emblocado em parafina, empregando o DNA Isolation Kit - Gentra System - Puregene, USA. Utilizou- se $1 \mu \mathrm{L}$ do DNA, sendo a reação realizada conforme De Grave et al. ${ }^{14,15}$. Como controle positivo foi empregado 1ng de DNA genômico de Leishmania $s p$.e como controle negativo a reação foi realizada sem DNA (Figura 4).

O exame otorrinolaringológico revelou processo inflamatório ulcerado e com tecido de granulação sugestivo de LTA.

Foi tratada (em dezembro de 2004) com antimoniato de n-metilglucamina (Glucantime ${ }^{\circledR}$ ) na dose de $20 \mathrm{mg} \mathrm{Sb}^{\mathrm{v}} / \mathrm{kg} /$ dia durante 30 dias, havendo melhora progressiva das lesões. Em maio de 2005 apresentou cura clínica das lesões (Figura 5).

\section{DISCUSSÃO}

As formas tegumentares da leishmaniose do Novo Mundo compreendem manifestações clínicas que dependem de alguns fatores, como a espécie de

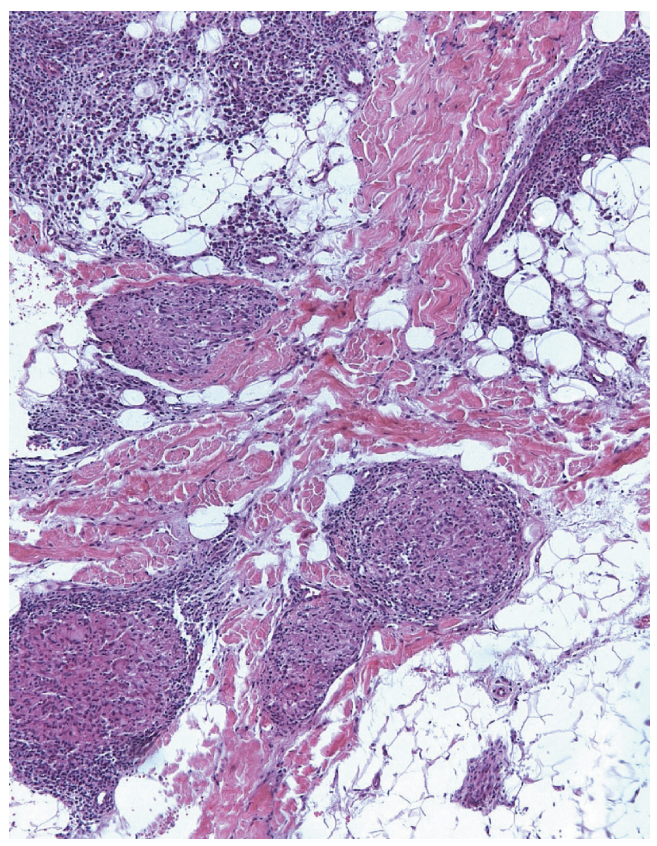

FIGURA 2: Reação exudativa e granulomatosa, observando-se granulomas sem necrose tecidual (Reação tipo 4 segundo descrição de Magalhães et al, 1986) (HE 100x)

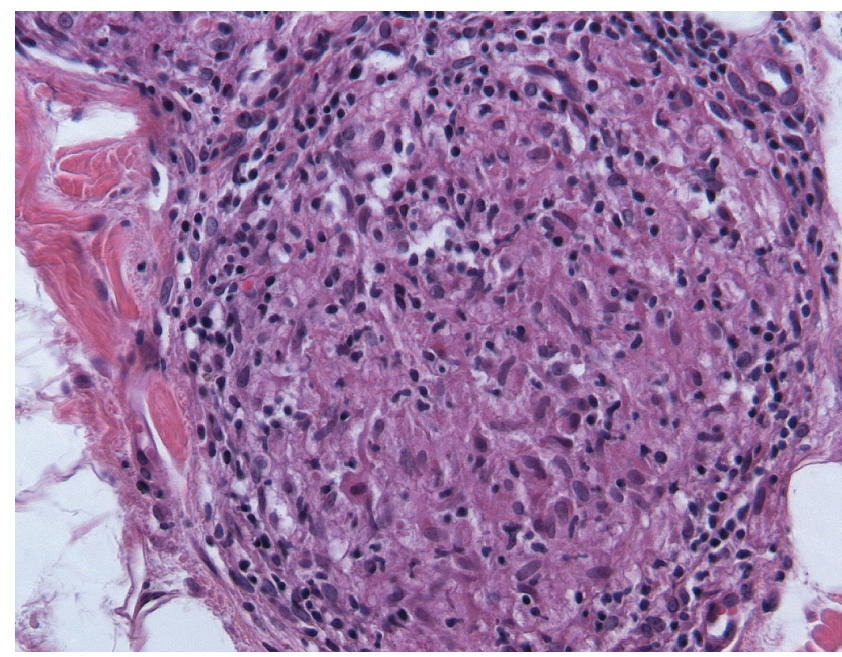

Figura 3: Detalhe de um granuloma tuberculóide denso (HE 400x)

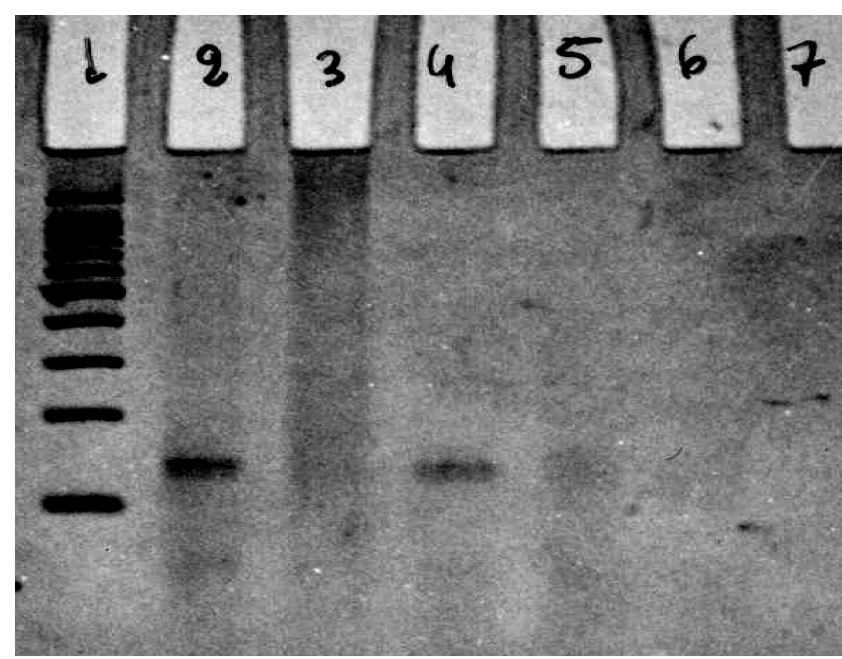

Figura 4: 1. PM 100pb (marcador de peso molecular de 100pb-Gibco-BRL); 2. Amostra diluída 1:10 (paciente); 3. Amostra sem diluição (paciente); 4. Controle positivo (1ng de DNA de formas de cultura de Leishmania sp); 5. Controle negativo (reação sem DNA); 6. Controle negativo (reação sem DNA - controle do ambiente)

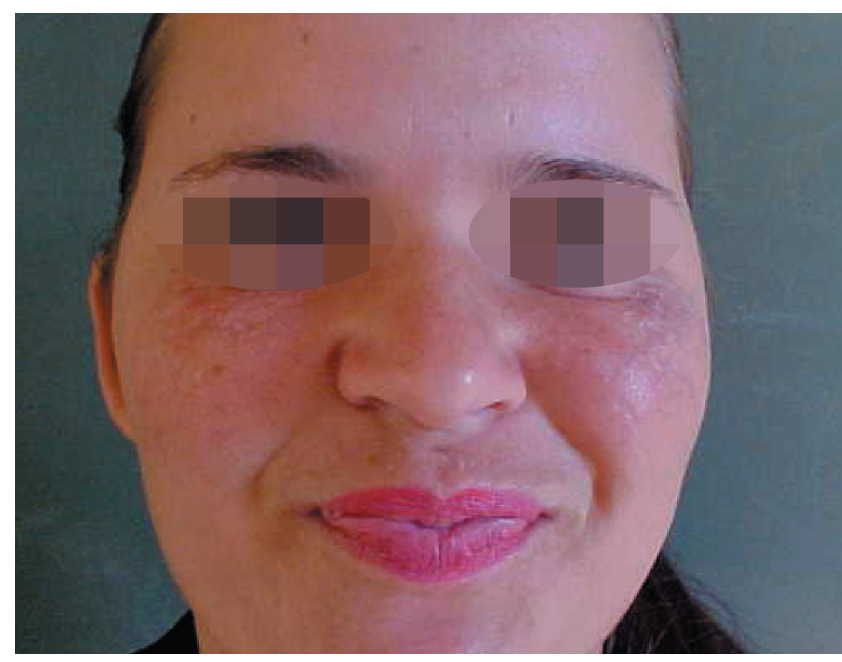

FiguRA 5: Aspecto da face, após cura clínica, em maio de 2004 
Leishmania envolvida e a relação do parasito com seu hospedeiro. ${ }^{5}$ A LTA produz amplo espectro de lesões, o que torna o diagnóstico clínico nem sempre simples ou imediato. ${ }^{14}$

$\mathrm{Na}$ leishmaniose cutânea, o diagnóstico clínico pode ser confundido com outras doenças não relacionadas, como hanseníase, sífilis, esporotricose e outras. Neste caso, a PCR mostrou-se útil na identificação do parasito, permitindo diagnóstico preciso, fator relevante no prognóstico do quadro clínico. A detecç̧ão de seqüências de DNA específicas de patógenos representa uma das mais importantes contribuições da PCR na epidemiologia e na clínica de doenças infecciosas. ${ }^{14}$

No Brasil e em outros países do Novo Mundo a LTA constitui problema de Saúde Pública. Sua importância reside não só na alta incidência e ampla distribuição geográfica, mas também na possibilidade de assumir formas que podem determinar lesões destrutivas, desfigurantes e também incapacitantes, com grande repercussão no campo psicossocial do indivíduo. $^{16,17}$

Os autores consideram importante relatar esse caso de LTA, de apresentação pouco freqüente e chamar atenção para o fato de que, apesar de a PCR ser exame ainda de pouco acesso e caro, em situações especiais ele pode ser bastante útil.

\section{AGRADECIMENTOS}

A Neusa Lúcia Dias da Silva e a Rosângela de Fátima Gomes pelo apoio técnico. 


\section{REFERÊNCIAS}

1. Furtado T. Leishmaniose Tegumentar Americana. In: Machado-Pinto J. Doenças infecciosas com manifestações dermatológica. Rio de Janeiro: Médica e Científica; 1994. p. 319-28.

2. Lainson R., Shaw JJ. Evolution, classification and geographical distribution. In: Peters W, Killick-Kendrick R. The leishmaniasis in biology and medicine. London: Academic Press; 1987. p. 1-128.

3. Shaw JJ. The relatonship of sand fly ecology to the transmission of leishmaniasis in South America with particular reference to Brasil. In: Burger J, editor. Memoirs on entomology, international. Florida: Associated Publishers; 1999.

4. Saude.gov.br [homepage]. Brasília: Ministério da Saúde, Tópicos de Saúde. Leishmaniose Tegumentar Americana. Data de acesso? Available from: http://www.portal.saude.gov.br/portal/svs/

5. Saravia NG, Valderrama L, Labrada M, Holguín AF, Navas C, Palma G, et al. The relationship of Leishmania braziliensis subspecies and immune response to disease expression in New World leishmaniasis. J Infec Dis. 1989;159:725-35.

6. Bolognia JL, Jorizzo J, Rapini RP. Dermatology. London: Mosby; 2003. p. 1295.

7. Manson-Bahr PE. Diagnosis. In: Peters W, KillickKendrick R, editors. The leishmaniasis in the biology and medicine. London: Academic Press; 1987. p. 703-28.

8. Furtado T. Critérios para diagnóstico de LTA. An Bras Dermatol. 1980;65:51-86.

9. Magalhães AV, Moraes MAP, Raic NA, Llanpos-Cuentas EA, Costa JML, Cuba-Cuba CA, et al. Histopatologia da leishmaniose tegumentar por Leishmania b. braziliensis. Padrões histológicos e estudo evolutivo das lesões. Rev Inst Med Trop Sao Paulo. 1986;28:253-62.

10. Fundação Nacional de Saúde. Guia de controle da leish maniose tegumentar americana. Brasília: Ministério da Saúde; 2000.

11. Brujin MHL, Barker DC. Diagnosis of new world leishmaniasis: specific detection of species of the $\mathrm{L}$. braziliensis complex by amplification of kinetoplast DNA. Acta Trop. 1992;52:45-58.
12. Eresh S, McCallum SM, Barker DC. Identification and diagnosis of Leishmania mexicana complex isolates by polymerase chain reaction. Parasitol. 1994;109:423-33.

13. Gontijo B. Reação em cadeia da polimerase (PCR) no diagnóstico da Leishmaniose Tegumentar Americana [Tese]. Belo Horizonte: Universidade Federal de Minas Gerais; 1997. p. 91.

14. De Grave W, Fernandes O, Campbell D, Bozza M, Lopes U. Use of molecular probes and PCR for detection and typing of Leishmania- a minireview. Mem Inst Oswaldo Cruz. 1994;89:463-9.

15. Garcia FCB, Santos SSR, Chociay MF, Medeiros ACR, Roselino AMF. Métodos subsidiários para diagnóstico da Leishmaniose Tegumentar Americana (LTA): compara ção do seqüenciamento de DNA e da PCR-RFLP para determinação da espécie de leishmania em amostras cutâneo-mucosas. An Bras Dermatol. 2005;80 (Supl 3):S340-5.

16. Carvalho MLR. Aspectos da imunidade celular em pacientes com leishmaniose tegumentar americana, procedentes de área endêmica do Estado de Mato Grosso-Brasil, antes e após o tratamento com antimonial pentavalente. [Tese]. Belo Horizonte: Universidade Federal de Minas Gerais; 2000. p. 157.

17. Carvalho MLR, Fontes CJF, Hueb M, Guedes AM, Afonso LCC, Melo MN. Leishmaniose tegumentar no Estado do Mato Grosso (Brasil): estudo clínico, laboratorial e ter apêutico. An Bras Dermatol. 2002;77:45-56.

ENDEREÇO PARA CORRESPONDÊNCIA / MAILING ADDRESS:
Antonio Carlos Martins Guedes
Rua Padre Rolim, 515, Sala 708.
Bairro Santa Efigênia
30190030 - Belo Horizonte - MG
Tel.: 31 -3274-8400
E-mail: guedes@medicina.ufmg.br

Como citar este artigo / How to cite this article: Guedes ACM, Carvalho MLR, Melo MN. Leishmaniose tegumentar americana: apresentação pouco comum. An Bras Dermatol. 2008;83(5):445-9. 